NBSIR 75.669

Failure of Plexible Brass Gas Appliance Connectors

$\mathrm{J}, \mathrm{R}$. Ambrose and J. Kruger

Corrosion and Electrodeposition Section Metallurgy Division

Institute for Materials Research

National Bureau of Standards

Washington, D, C. 20234

February 1975

Failure Analysis Report

Prepared for

Office of Consumer Product Safeiy

Walter G. Leight, Chief

National Bureau of Standards

Washington, D. C. 20234 

NBSIR 75-669

\section{FAILURE OF FLEXIBLE BRASS GAS} APPLIANCE CONNECTORS

$J . R$. Ambrose and J, Kruger

Corrosion and Electrodeposition Section Metallurgy Division Institute for Materials Research National Bureau of Standards

Washington, D, C, 20234

February 1975

Failure Analysis Report

Prepared for

Office of Consumer Product Safety

Walter G. Leight, Chief

National Bureau of Standards

Washington; D. C. 20234

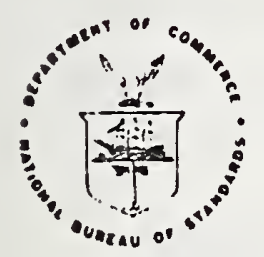

U. S. DEPARTHENT OF COMHERCE, Fredorick B. Dent, Socrotary 

Failure of Flexible Brass Gas Appliance Connectors

\section{BACKGROLND}

A written request was received from the U. S. Consumer Product Safety Commission (CPSC) by the Office of Consumer Product Safety at the National Bureau of Standards to analyze the failure of two flexible brass tubing samples provided by Bureau of Engineering Sciences under the 15 (b) Project (Fig. 1). According to the CPSC report which accompanied the request, the brass tubing was used as a flexible gas appliance connector and had failed within 3 to 6 weeks following installation. At the time of installation, proper sealing of the tubing couplings was verified by application of a blue liquid leak detector to the couplings and flexible tubing at either end of the connector. The report continued on to state that severe corrosion and rupture of the tubing connectors.by cracks penetrating the tubing walls occurred at those extremities of the connectors; where the leak detector would presumably have been applied. An independent analysis of the leak detector solution using gas chromatographic analysis was obtained by CPSC which reported the solution to contain a significant concentration of free ammonia.

A one gallon plastic container approximately three-fourth full of a clear blue liquid accompanied the two sections of tubing, and it was further requested that an opinion be given as to whether this solution could have been responsible for the reported corrosion of the brass tubing.

\section{VISUAL EXAMINATION}

Visual examination of the specimens revealed discoloration and blue and white residue in the area located near the extremities of the tubing sections, where couplings were attached (Fig. 2a). In addition to this, 

a large number of cracks had penetrated the tubing, and, since the CPSC report had pointed out the presence of ammonia in the leak detector solution, It was suspected that subsequent failure resulted from what is commonly called stress corrosion cracking (Fig. 2b). The residue appeared bluishgreen with rather large amounts of a crystalline white material as well (Fig. 3).

\section{INVESTIGATION AND RESULTS}

Analysis of Metal Composition

A $10 \mathrm{~cm}$ section of tubing was forwarded to the Chicago Spectro Service Laboratory for the metal composition analysis. Their results show the brass to be within the specifications of what is commonly called Admiralty Metal (see Table I). The specifications and compositional maxima and minima for Admiralty Metal are given in Table II (1). The Laboratory report is reproduced in Appendix A.

Metallographic Examination

Optical micrographs were made of a specimen which was sectioned from the flexible tubing in an area near one of the major fracture sites. Cracks can be observed throughout the body of the material and are highly branched (Fig. 4). When the specimen surface was chemically etched two important observations can be made: (1) the metal microstructure is of rather large grain size, and (2) the cracks are largely transgranular in nature, propagating through grains rather than through grain boundaries (Fig. 5).

Residue Identification

X-ray diffraction patterns were obtained from samples of the two types of residue, and attempts were made to determine their chemical composition. 

The blue material gave diffraction patterns which could not be unambiguously identified. However, a large number of the diffraction lines characteristic of tetramine cupric sulfate $\left(\mathrm{Cu}\left(\mathrm{NH}_{3}\right)_{4} \mathrm{SO}_{4}\right)$ were found. This particular compound would be expected to be present as a corrosion product when copper reacts with ammonia.

The white product also gave a large number of diffraction lines which could not be completely resolved. Certain similarities were observed between these patterns and certain organic compounds (e.g. stearates) to indicate the presence of an organic compound. The white product on the tubing foamed when distilled water was sprayed on the surface and gave an indication of alkaline $\mathrm{pH}$ when tested with $\mathrm{pH}$ indicator paper. Although not absolutely conclusive, these tests point to the probability that the white material may be some type of detergent. .

Leak Detector Solution Analysis

The seal was broken on the plastic bottle containing the blue leak detector solution; a strong odor characteristic of ammonia was immediately noticed upon opening the bottle. Two $100 \mathrm{ml}$ aliquots were withdrawn. One was reserved for our use in an exposure test and in a $\mathrm{pH}$ measurement. The $\mathrm{pH}$ was measured with a conventional glass electrode which gave a reading of 10.0. The other aliquot was sent to the Sadtler Research Laboratories for a total nitrogen and an ammonia nitrogen analysis. Results are given in Table III and show a high total nitrogen content as well as a significant concentration of ammonia nitrogen. The laboratory report is reproduced in Appendix B. 

The analytical technique used here gave approximately a 10 time higher concentration of ammonia than did the CPSC gas chromatography analysis. The Sadtler Laboratory procedure as given in Appendix B would give an estimate of the total available nitrogen as ammonia in the solution. As the $\mathrm{pH}$ of the solution is increased (by MgO addition), the equilibrium between $\mathrm{NH}_{4}^{+}$and $\mathrm{NH}_{3}$ would be shifted to the right (favoring $\mathrm{NH}_{3}$ liberation):

$$
\begin{array}{r}
\mathrm{NH}_{4}^{+}+\mathrm{OH}^{-}=\mathrm{NH}_{3}+\mathrm{H}_{2} \mathrm{O} \\
\text { DISCUSSION }
\end{array}
$$

\section{DISCUSSION}

Most brasses, and this includes Admiralty Metal, are susceptible to stress corrosion cracking in the presence of as little as trace amounts of ammonia in the atmosphere, providing four ingredients are present (2):
(a) ammonia or an ammonia derivative,
(b) water or water vapor,
(c) oxygen and
(d) stress.

The analysis of the leak detector solution reveals the presence of ammonia; water vapor and oxygen are always present in the atmosphere. The presence of residual stress, probably arising from fabrication of the tubing or from flexing during its installation, was verified through the mercurous nitrate test (3) (see Fig. 6).

A comparison of the optical micrographs taken of cracks in this material (Fig. 5) with those observed for stress corrosion cracking of $70-30$ brass in non-tarnishing aqueous ammonia solution show the morphology of cracking to be quite similar (Fig. 7, from (4)). Furthermore, the particular heat treatment of this brass which resulted in the large grain size (Fig. 5) 

would be expected to cause an increase in susceptibility to stress corrosion cracking (5).

Finally, a test specimen was cut from a section of the brass tubing, bent once to simulate treatment during installation of the coupling unit, dipped into a sample of the leak detector solution, then placed into a sealed glass container. The test exposure was allowed to proceed for two weeks, after which the specimen was removed, sectioned, and mounted for metallographic examination. Although the extent of crack propagation is less than that in the failed specimens, the initial stages of cracking are evident in Fig. 8. It should be remembered that service failures were reported to have taken from 3 to 6 weeks to occur, while the short term laboratory test was all that was possible, within the time limitations set to prepare this report.

\section{CONCLUSIONS}

From the results of the failure analysis performed on the brass tubing supplied, from the chemical analysis of the leak detector solution, and from the simulated exposure test in this laboratory, it is concluded that failure resulted from the stress corrosion cracking of flexible Admiralty Metal tubing due to the combined effects of residual stress and ammonia, oxygen and water vapor. 



\section{BIBLIOGRAPHY}

1. Metals Handbook, T. Lyman, Editor, p. 920 (American Society for Metals, Novelty, Ohio, 1960).

2. D. H. Thompson, Stress Corrosion Cracking of Metals - A State of the Art, STP 518, p. 39 (American Society for Testing and Materials, Philadelphia, 1972).

3. 1974 Annual Book of ASTM Standards, Part 6, Designation B 154-73, p. 278 (American Society for Testing and Materials, Philadelphia, 1974).

4. E. N. Pugh, J. V. Craig, and A. J. Sedriks, Proc. of Conf. on Fund. Aspects of Stress Corr. Cracking, OSU, Columbus, Ohio, p. 135 (National Assoc. of Corr. Engineers, Houston, 1969).

5. G. Edmunds, Symposium on Stress Corr. Cracking of Metals, p. 67 (ASTM-AIME, 1945). 



\section{TABLE I}

Copper

Tin

Zinc

Iron

Others Tota1

$71.03 \%$

0.90

28.00

0.01

0.10

\section{TABLE II \\ Miximum}

Minimetm

Minimum

Copper

$70.00 \%$

$73.00 \%$

Tin

0.75

1.20

0.06

Lead

Others Total

Zinc

TABLE III

Ammonia N

Total N

$1.175 \%$ by weight

$7.26 \%$ by weight 

Appendix A 

February 18,1975

REPORT OF ANALYSIS

\begin{tabular}{|c|c|c|c|}
\hline SAMPLE: & One (1) & FROM: & $\begin{array}{l}\text { U.S. Department of Commerce } \\
\text { National Bureau of Standards }\end{array}$ \\
\hline RECEIVED: & February 3,1975 & & Washington, D.C. 20234 \\
\hline
\end{tabular}

LABORATORY NO: 80792 ATTN: Dr. J. R. Ambrose

B243 Bldg. 223

SUBJECT:

One ( 1 ) sample of "Leak Test Solution"

REQUEST:

Determination of ammonia and total nitrogen content

RESULTs:

Ammonia nitrogen as $\mathrm{N}, \%$ by wt.

1.19

7.31

Total nitrogen as $N$, \% by wt.

COMMENT:

The above reported results were corrected for reagent blank determinations. The analyses were conducted in duplicate.

Ammonia nitrogen was determined by distillation of weighed portions of sample in the presence of magnesium oxide. The distillates were recovered in boric acid and titrated to methyl red end point with standardized hydrochloric acid.

Total nitrogen was determined by the Kjeldahl digestion method using the distillation procedure described above.

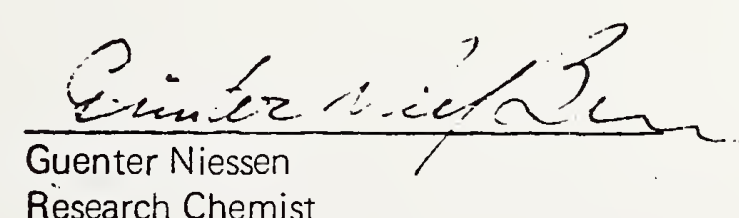

GN:bs 



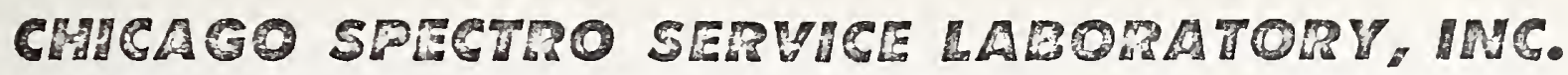 spectrographic and Chemical Analysts \\ Metallurgists}

4848 S. KEDZIE AVE. - CHICAGO, ILL. 60632

ALYSIS REPORT FOR:

AREA CODE $312-523-7088$

U.S. Department of Commerce National Bureau of Standards Washington, D. C. 20234

Attention: Mr. John R. Ambrose, Corrosion and Electrodeposition Section

Sample: Flexible Brass Tubing

Copper

Tin

Zinc

Iron

Others Total
$71.03 \%$

0.90

28.00

0.01

$<.10$
DATE

Feb. 5, 1975

Report No. 6363

PURCHASE ORDER NO.

\section{Report No. 6363}





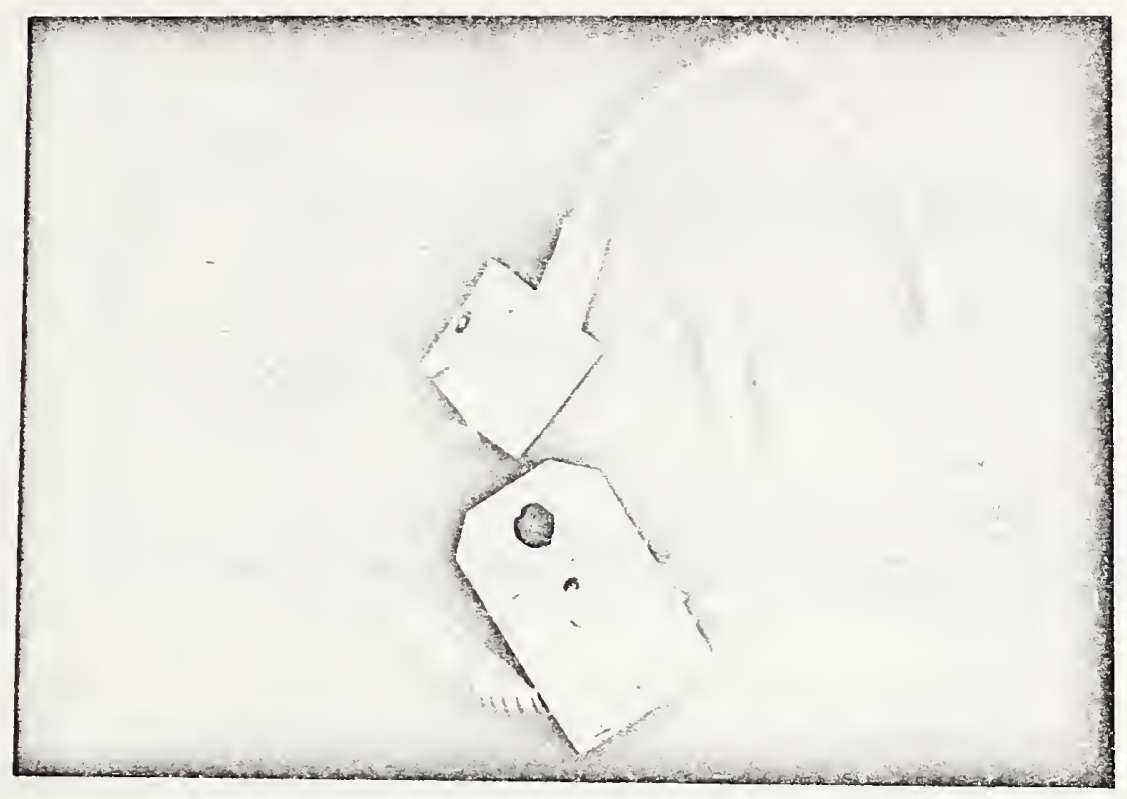

Fig. 1 Photograph of the two flexible brass samples. 



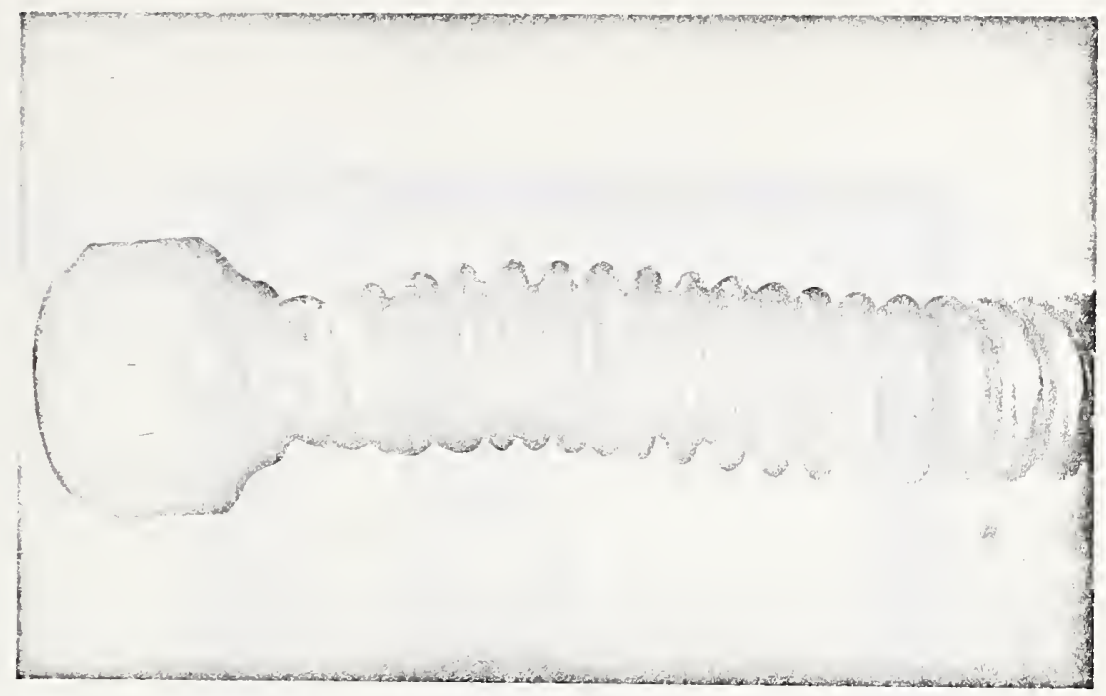

Fig. 2a Close-up view of an end of one tubing, showing where the corrosion attack was located.

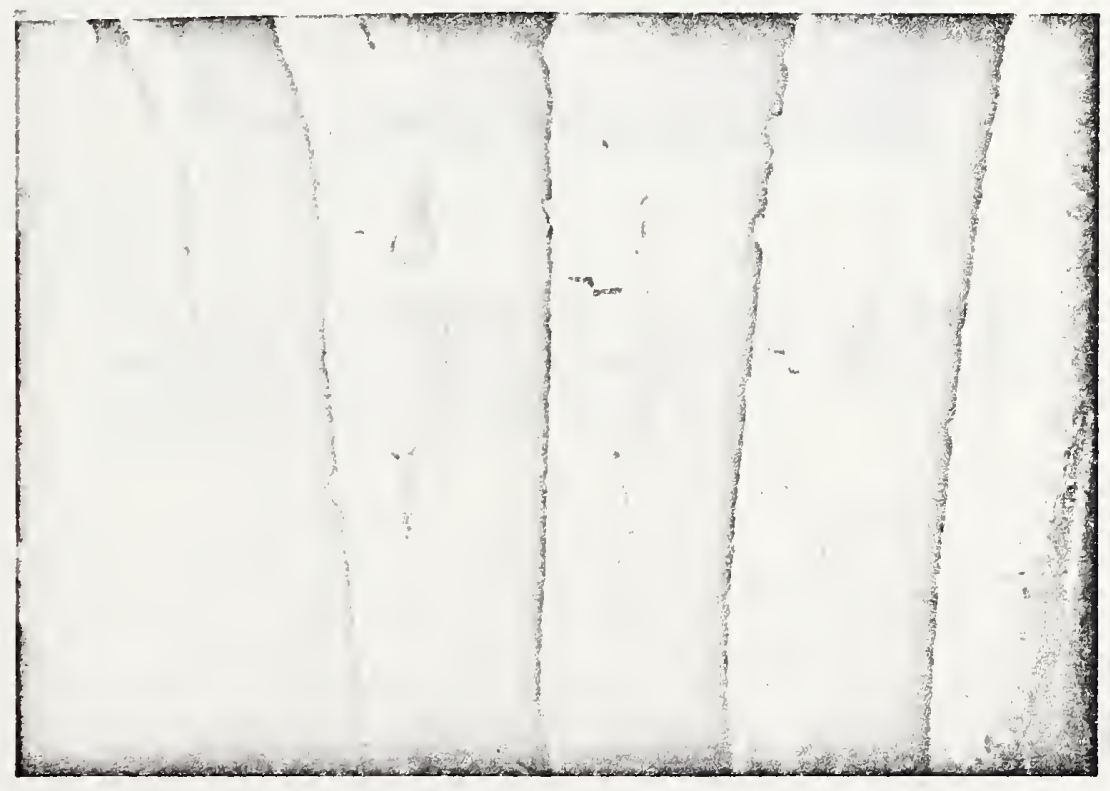

Fig. 2b Close-up photograph of an end of a tubing sample, showing the severe cracking of the brass. 



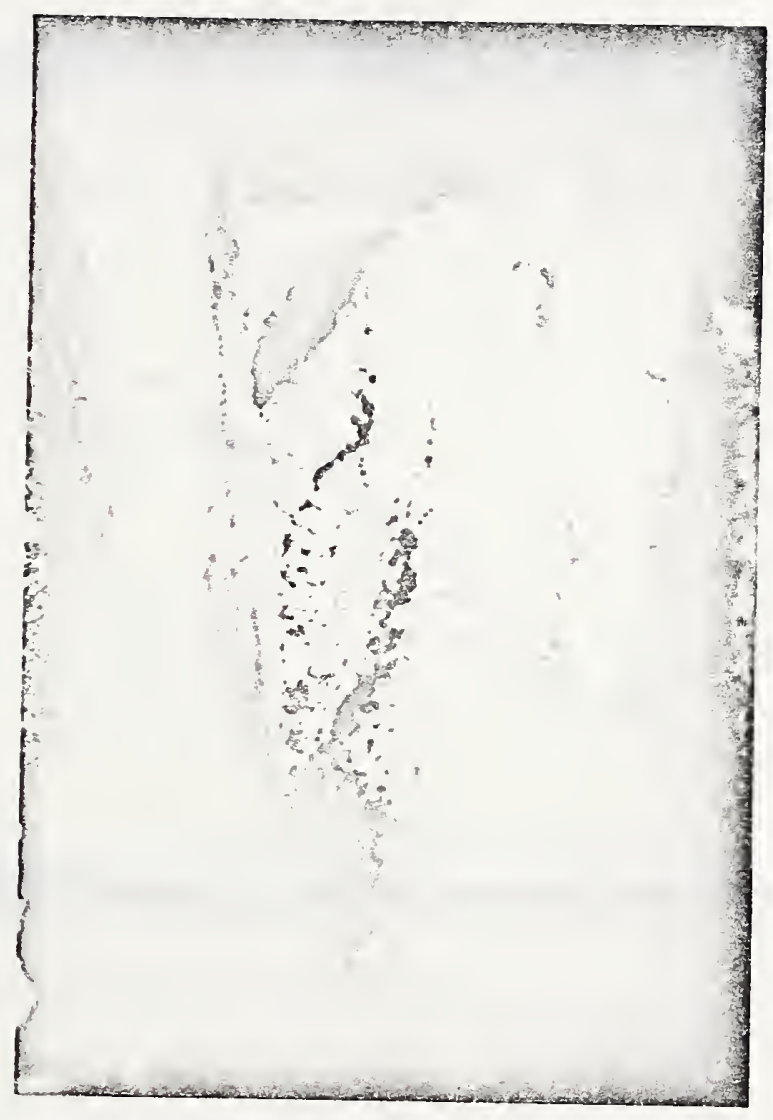

Fig. 3 Close-up photograph of the corrosion product on the brass tubing, showing both the white and the bluish-green materials. 



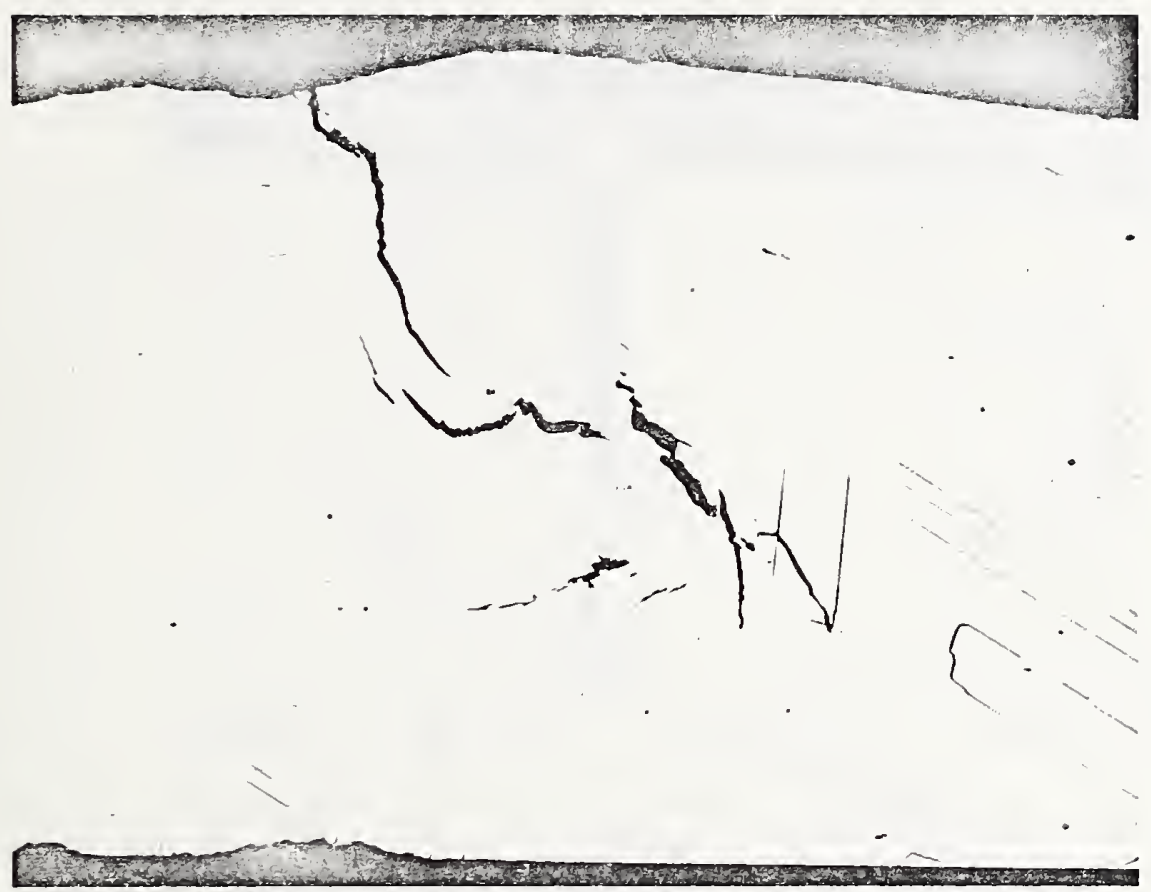

Fig. 4 Optical Micrograph (x200) of a cross section of the flexible brass tubing, showing the branched nature of the cracks. 



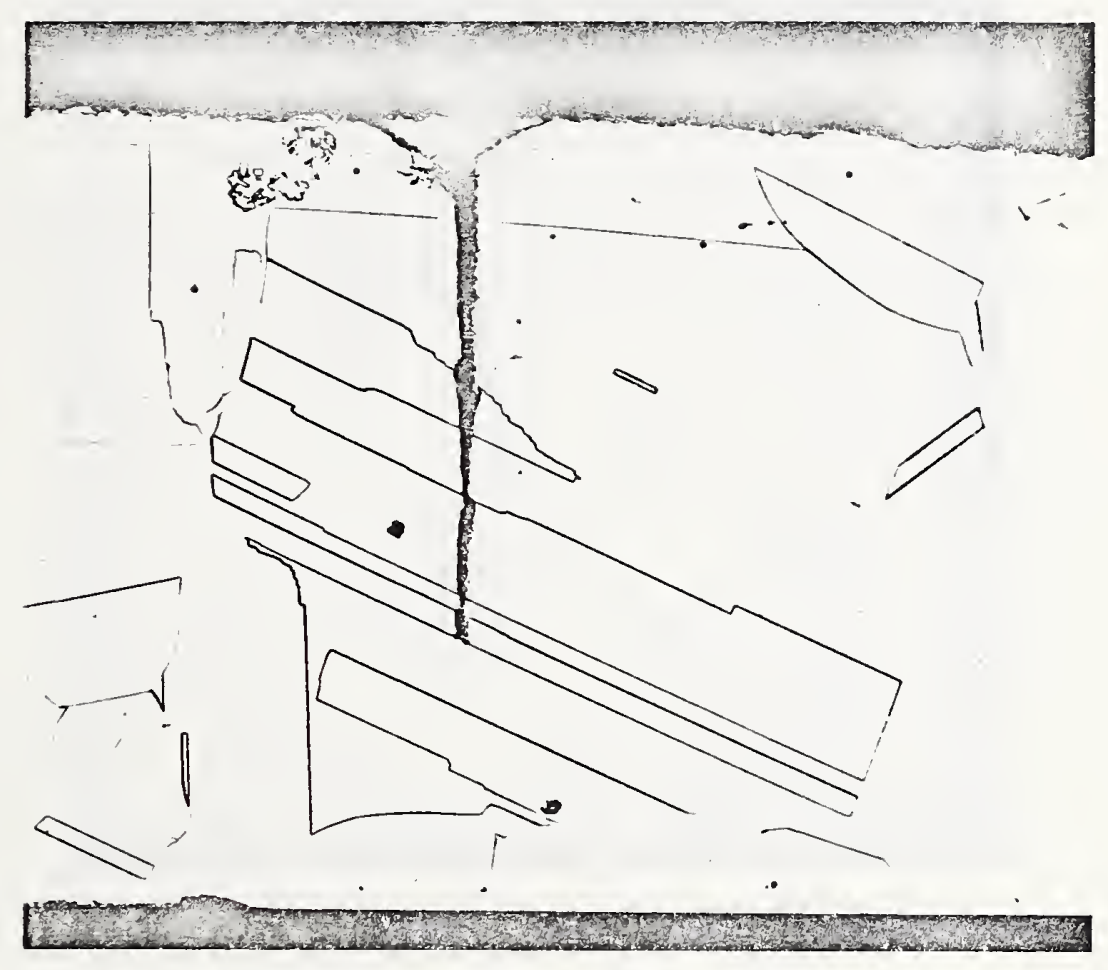

Fig. 5 Optical Micrograph (x200) of a cross section of the flexible brass tubing, etched in 1 part water $\left(\mathrm{H}_{2} \mathrm{O}\right), I$ part hydrogen peroxide $\left(\mathrm{H}_{2} \mathrm{O}_{2}\right)$, and 1 part concentrated ammonium hydroxide $\left(\mathrm{NH}_{4} \mathrm{OH}\right)$, showing the metal microstructure. Cracks are predominantly transgranular. 



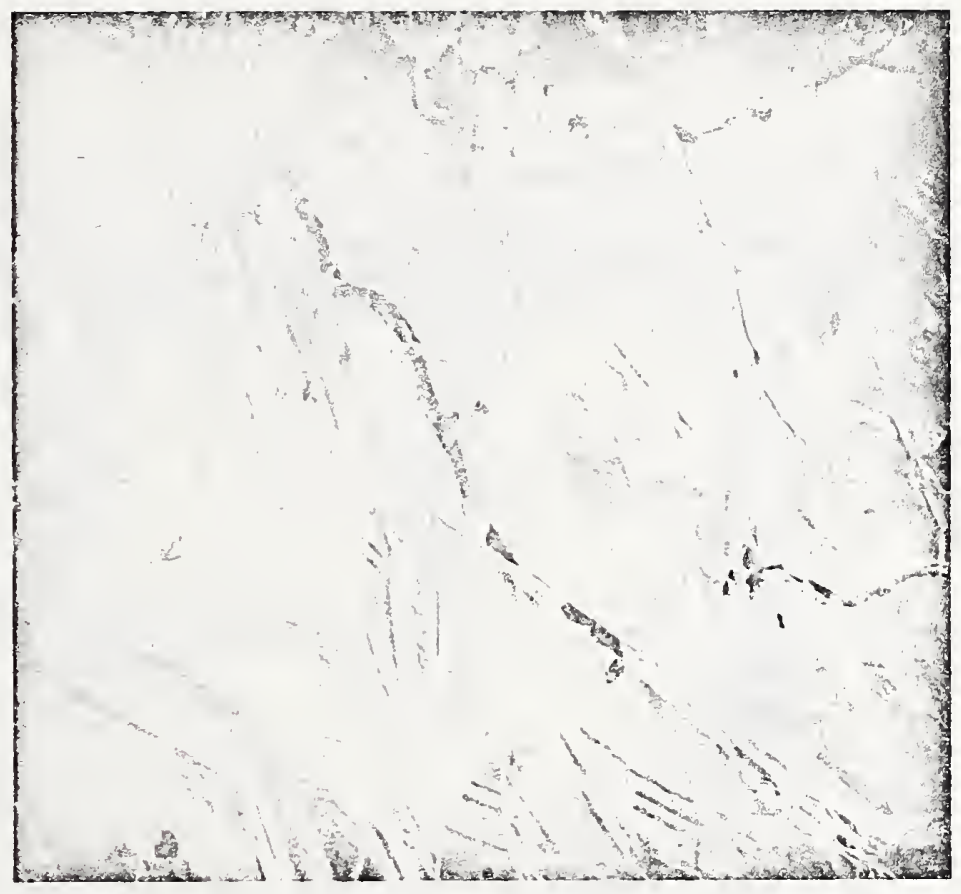

Fig. 6 Scanning Electron Micrograph (x90) showing cracks in a flexible brass tubing specimen after exposure in the mercurous nitrate test. Cracks indicate presence of residual stress. 



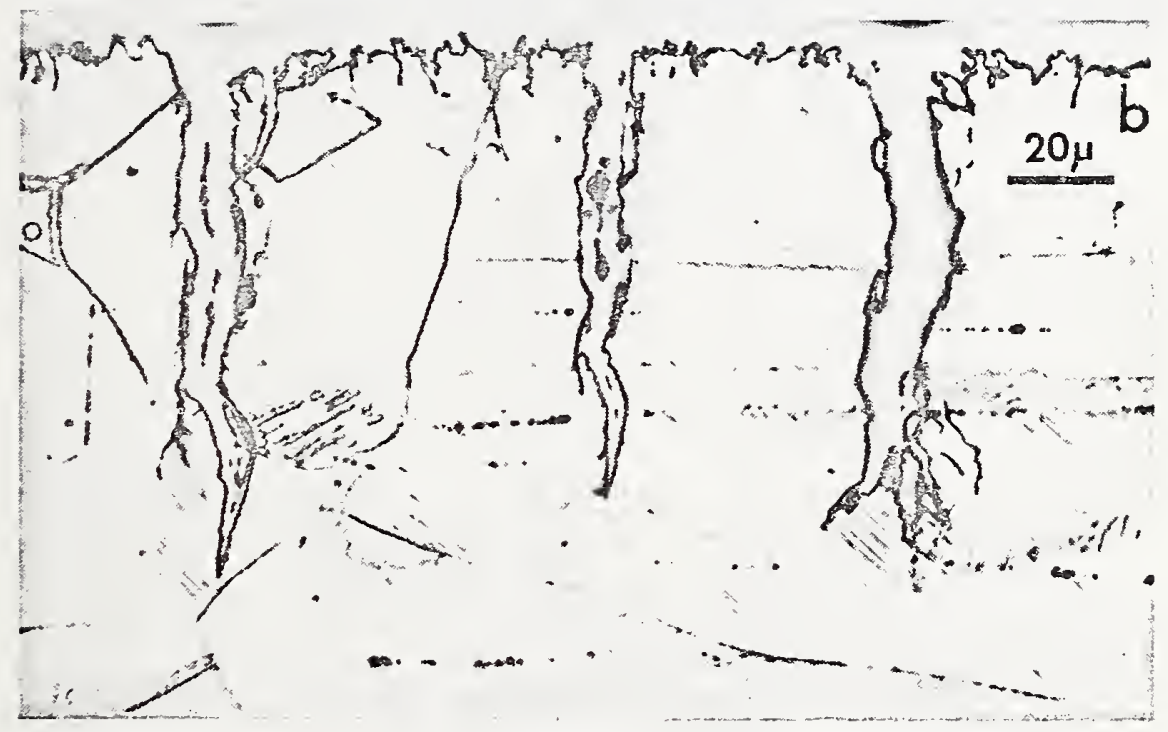

Fig. 7 Optical Micrograph showing stress corrosion cracks in 70-30 brass exposed to aqueous ammonia solution (from (3)). , 



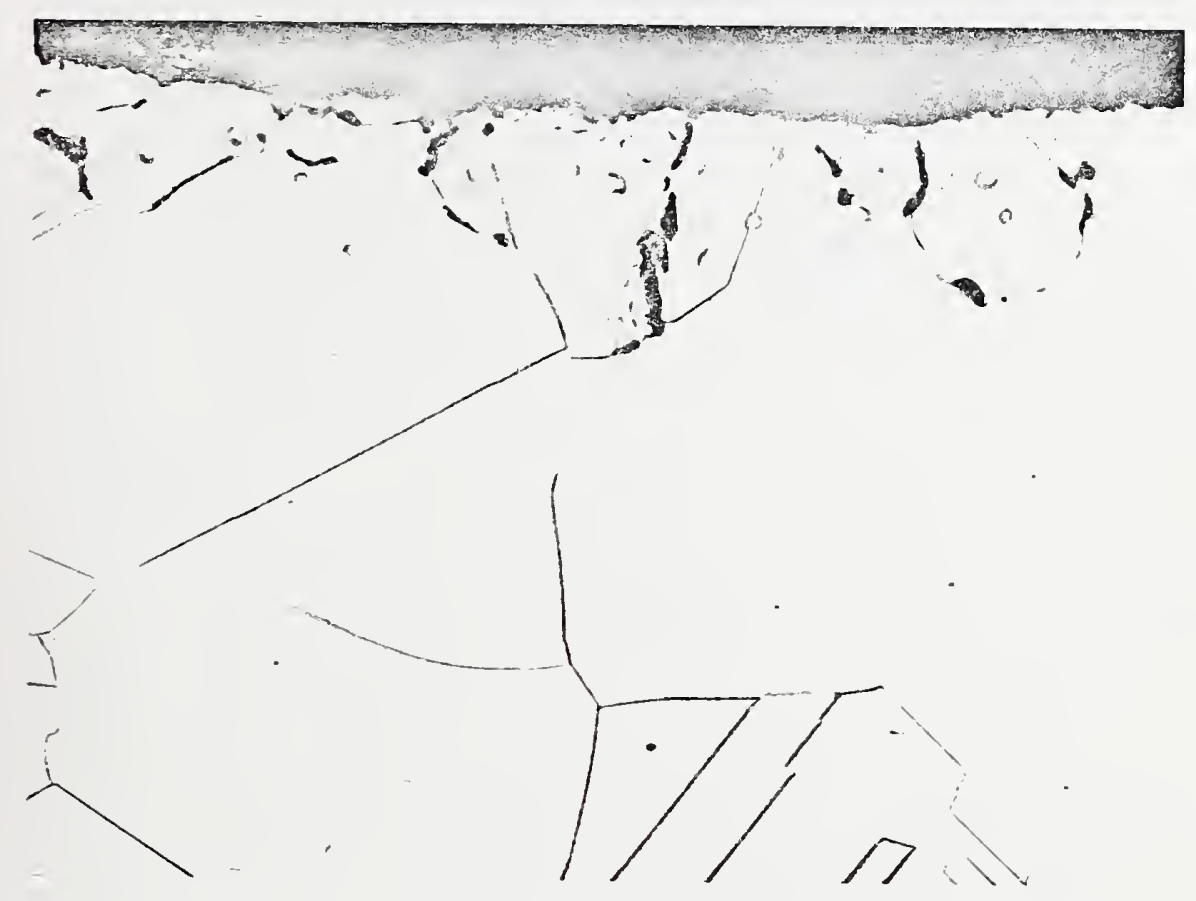

Fig. 8 Optical Micrograph $(\times 500)$ of the cross section of a $5 \mathrm{~cm}$ specimen of brass tubing exposed for two weeks to the leak detector solution, then etched as in Fig. 5, showing initiation of cracking at the metal surface. 
